\title{
Critique of Axiological Reason: Why the Idea of Values has Achieved the Totality in Modern Culture
}

\author{
Sergey Evgenievich Yachin \\ Department of Philosophy, School of Humanities, Far Eastern Federal University, Vladivostok, Russia
}

\section{Email address:}

yachin.se@dvfu.ru

\section{To cite this article:}

Sergey Evgenievich Yachin. Critique of Axiological Reason: Why the Idea of Values has Achieved the Totality in Modern Culture. International Journal of Philosophy. Vol. 7, No. 1, 2019, pp. 31-40. doi: 10.11648/j.ijp.20190701.15

Received: January 1, 2019; Accepted: February 11, 2019; Published: March 1, 2019

\begin{abstract}
The article deals with the question of applicability limits of the Value Theory in cultural studies and validity limits of contemporary value-based consciousness. This limit is set by differentiating between the Good and the Value; the difference was clear to ancient Greek and medieval philosophers, and the necessity of acknowledging which is returning to the philosophy today. The Good exists independently, it is a source of life and, therefore, supposes gratitude; values and evaluation come into question when "there is choice and its declination, when it is up to us to choose between action and inaction". But the fact is that collective consciousness is now dominated by axiological rationality. Gnoseologically, the characteristic of this rationality is the substitution of the classical idea of truth by evaluation. Contemporary philosophy sees the question of how these or those Values emerge as a field of the critical analysis. No prominent school of philosophical thought places critical importance on Values, but Values are regarded as derivatives from various foundations: interests of a social class or a group, structures of the unconscious, language or communication logic, the nature of human existence, the sense of being. Consequently, axiological reason is seen as mythologically "naive", which is also a reverse side and a victim of cynical reason. Theories, that attempt to define Values as foundations of the culture, reflect naivety of collective consciousness. Their major theoretical drawback is of the same nature: they oversee the difference between the Value and the Good. The author analyzes the essence of culture from the hermeneutical point of view, according to which culture is based on comprehension of meanings constituted by language, and Values are just what meanings manifest themselves through.
\end{abstract}

Keywords: Axiological Rationality, The Good and the Value, Sense and Value, Cynical Reason, The Mythology of Values

\section{Introduction}

The name of the article being suggested is a tribute to tradition. To be more exact - this work is about axiological rationality that dominates in contemporary culture and that, if not to focus on differentiation of reason (Vernunft in German) and understanding (Verstand in German), within the given context, I suggest to consider as a special synonym of practical rationality. This is the "rationality" that bases on specific judgments being named "phronesis" ( $\left.\varphi \rho \operatorname{cov} \sigma \iota_{\varsigma}\right)$ by Aristotle: "[mental] temper involved with the judgment, that is true and supposing actions that concern the human's Goods" [as stated in Nicomachean Ethics], as well as "that concern the things connected with the activities when there is choice and evasion, whether doing something or not doing anything depends on us" [5 (NE, 1197a)]. Taking into account this subtlety, this work is addressed to the philosophical community, whose members' professional competence implies knowledge of the history of philosophical thought. This knowledge allows to be aware of the historical circumstances under which this or that topic, subject, or problem was being formed and, therefore, gives the author an opportunity to reduce on explaining why the historically formed subject suddenly starts to lose its actuality. This directly concerns the problem of formation and decline of the topic of the Value in philosophy. A professional philosopher (who immanently takes the historical position), knowing that the problematics of the Values was not expressed as the concept neither in ancient Greece nor in Middle Ages, cannot simply state that "Plato, Aristotle and other great philosophers, when developing problems of ethics, aesthetics, economics and etc., dealt with 
the Values, but they did not realize that the Good, the Beauty, the Usefulness and etc. had something in common that should become the subject of a separate discipline" "; he/she shall understand why the thinkers of these epochs did not consider the being of the person to belong to the category of the Values and, moreover, did not intend to create the ontology of the Values. It will be almost enough for us to clarify this issue to understand that the modern philosophy refuses to universalize the Values (an essentially axiological vision of a person and the world) on the same grounds as Plato and Aristotle together with Plotinus, Nicholas of Cusa, and Thomas Aquinas used to do. The key question here is why the epochal comprehension of the God and the Being acting as the Good is not just extremely distant from the comprehension of the Value in the mind of a modern person, but why it has directly opposite (opposite in sign) meaning and because of this it can create an illusion of commonness. Though, today a religious Christian (but at the present day such people do not define the spiritual mind of the epoch) will still agree with Heidegger's words that "When "the god" is finally declared to be "the supreme value", then this is depreciation of a godly creature. The way of thinking in the values here and in all other things is superior sacrilege that can exist only with regards to the being" [2].

\section{The Good and the Value: On Methodology of the Approach}

\subsection{The Ontology of the Good and the World of the Values: How Thinkers of Ancient Greece and Middle Ages Looked at These Things}

If Plotinus or Thomas Aquinas were our contemporaries, they, perhaps, would agree with Heidegger's idea that it is impossible to refer to the God as the Value, even if it is "the Supreme Value". Within both patristic and scholastic traditions, the God is not the Value, but it is the basis of a possibility for their existence [3]. Both ancient Greek and Middle Age thinkers used to differentiate the Good "in itself, that creates all the rest" and "those things that we consider to be Good" [4 (The Enneads 7) $]^{2}$. The typical example of the Supreme Good for the mind of that time was the Sun that exists in itself and "shines as it wants". What "the one being shined at" thinks about it, and what it considers to be the Good - this question, being extremely topical from the pedagogical point of view, represents a secondary issue from the point of view of ontology and perception of the Truth. The idea of the Good as the thing in existence was covering all variations of what a person considered to be the Good. The following classification of the Goods, that has been generated by Aristotle, is very illustrative: "The Goods can be valued, appraised, probable" $\ldots$ < and those $>, \ldots$ "that create other Goods" [5 (Great Ethics, 1183b)].

1 This expression belongs to A. Stern. Cit.ex.: [1]

2 The meaning of Plotinus's study in this case is rather illustrative, because it is a place where ancient Greek and Christian philosophies dispart.
Further history of the mankind, (if to agree with Hegel that it also was "progressive in the consciousness of freedom"), had a side-effect in the form of full expansion of the human's self-will, in the result of which, each person got the right "to have his own opinion". Now what a person considers to be the Good - has become the frames of reference of what the Good in itself is. Moreover, the issue on the Pure Good has lost any important significance in the society of plurality of opinions and tolerance. As Jean-Luc Nancy said, though "there is no such human nature with the help of which it would be possible to identify or conclude how a person shall live, have his/her rights, his/her politics, his/her ethics... for us (in "the West") such human nature has really disappeared" [6]. In what sense can we (and whether we can!) talk about common Values of a society that is legally divided onto religious and irreligious people, people who believe in different gods, people who follow traditional family values and people who deny them, conservatives and progressists, liberals and communists, and so on and so forth? And this, by the way, presents a consequence that any generalization about the Values of an exact society or exact culture, any attempts to bring them to somewhat common denominator or encapsulate them into an exact matrix - won't be very accurate in the theoretical point of view.

The circumstance, that was left by ancient classic Greek authors without due attention, shall be comprehended. Assuming, as Aristotle, that the nature of a person implies his/her aspiration to some Good (it is impossible for a person to desire misfortunes for oneself), it is impossible to understand how the Pure Evil becomes a target of a subject and a specific Value. This topic has become the object of intense interest of the modern philosophy. (Illustrative works here are the following: J. Baudrillard "La Transparence du Mal" [7], G. Bataille "Literature and Evil" [8], A. Badiou "L'Éthique. Essai sur la conscience du mal" [9]). This is the factuality that makes us flatly admit that the process of formation of subjective Values has an absolutely different logic than the natural aspiration of a person to the Pure Good. We have to admit that the Pure Good and the process in the result of which the Values appear are not the same things. Only because of this, the investigation of the Values, but only as the investigation of the process in the result of which they are being formed, can act as a subject-matter of a special theory [10]. Also for this reason that the Values have a secondary character (in comparison with the Pure Good), the Value Theory cannot act as a foundation of both the theory of culture and the philosophy of a person.

The article will clarify, as far as it is possible, the way of thinking that implies that thinking of the God and the Being as the Value is "utmost sacrilege". In brief, the core of this way of thinking is to consider the Being and the Life as the Blessing, i.e. the gift that shall be regarded with gratitude. The idea of the Good in the times of ancient Greece and Middle Ages had an essentially ontological character, the Being is the Good, because all things exist thanks to their connection with other things in existence.

This is a simple line of thinking that leads to such 
differentiation. The sun, air, and water represent the Pure Good for those who live and are in need for light and warmth, for those who suffer thirst and breathe. And, nevertheless, these things represent individual Goods: there are such things or such people who are not in need for these things in their lives. However, as Plato says, there is: "The Supreme Good that gives life to everything". What will be if a person does not consider the Good to be the Good and if this person considers the things to be Good that actually do not represent the Good? This is the question of ancient Greek and Christian ethics. Their educational task was focused on correcting false opinions (that existed in the form of "the Goods that were appraised and valued"). The only "naivety", that these thinkers really had, was that they could not even imagine that "false opinions" could gain the status of the legitimate Good. The things that, obviously, cannot act as the Good for life (for example, narcotics) can have a status of the legitimate Good (and the Value!) for this or that group of people. If in the times of ancient Greece and Middle Ages, the Pure Good acted as the scope of what an individual considered it to be, then starting from Renaissance, an individual's right to have his/her own idea about the Good is gradually becoming the frames for understanding what the Good is (in itself). And there occurs a situation to define which A. MacIntyre used an exceptionally concise and exact name: "After Virtue" [11]. This is what the quintessence of axiological reason is. First, this reason radically differentiates natural and artificial order of things, isolates the latter into a special kingdom of culture in order to announce it the kingdom of Values. To do that, one needs to take away from the Nature its physical origin and think that only mechanical relations can be there.

Ancient Greek and Christian thinkers in all variations thought of the Being in a teleological way. All things in existence were considered to have their own assignments and, in this sense, they represented the Good Being. It is needed to capture in mind the simple circumstance that targeting (being genetically first) together with the subjective need will be considered to be Good. But one thing is to think that this is the natural order of things (the universe, the nature) whereas a person himself/herself acts as its part, and another thing is when an assigned order is removed from the Nature and remained only in the world of Culture: then the Good takes the form of subjective Values, the subject of choice or, as Aristotle says: "the goods being valued and appraised". And now even natural Goods of life (the same "the sun, air, and water") take the form of subjective Values, the subject of some quasi-choice.

The thinkers of that time did not separate the study "on the things in existence as the things in existence" from the things in existence as the Goods. It is possible to state that the category of the Value (the things that we consider to be the Goods) have not been crystallized into a separate section, because it was completely consumed by the idea of the Pure Good. A person of that time was harmoniously thinking: I exist thanks to my parents, fruits of the earth, care of the people near me, and the Creator, and I express gratitude to them for these things. This is the formula of a religious way of thinking. And a modern individual will put "value" instead of "express gratitude" ("... I value them for these things"), and that's where the moral catastrophe of secularizing consuming consciousness is. Starting with the Modern Times, right on the basis where an idea of an autonomous subject was being formed, the relation of the Grace and the Evaluation (the Goods and the Values) is being turned over. And now the idea of the Value consumes everything that used to be considered as the Pure Good. A modern individual really does not catch the difference between "I love" and "I value", and if this person is religious - then he/she thinks of the God as the Supreme Value (in ascending order from the value of an omelette to a God-given-gift).

In its ontological status the idea of the Pure Good acted as a foundation for ethics too, this is most pronounced in Christianity, to the extent and because it states: "God is love". The Good as love and the Good as Value, though can intersect, but, in accordance with their regulatory principle (idea) - are completely opposite. To tell a person you love "you are my value" is as humiliating as to announce the God to be the Supreme Value. But the consciousness, that is penetrated with axiological attitudes, remains deaf to this differentiation. For it - to love is to value, i.e. to make it the object of his/her free choice. Real significance of axiology, in justifying it within the history, is focused around explaining this right of the subject to stand in this subjective opposition (Heidegger) to the world, hereby getting this very right of choice, illusionally thinking that this choice manifests his/her freedom. In the same degree as subjectivity is governed by imperative: "you must - because you can" (Kant), it has to give up on any axiological point of view - because here occurs a conflict of Values - and it neutralizes each of them and places the subjectivity into the space of pure existence as the person's own capability to go-beyond-oneself. And this is exactly what the manifestation of freedom is! $[12]^{3}$.

The modern epoch (to a great extent thanks to successful results reached by natural sciences in such spheres as cosmology, genetics, and information science) has one more time included into the agenda the issue on how strong the reasons, that extract the world of culture (techne) from the world of nature (physis) so radically, are, and this is done when the technologies and the information transfer processes, undoubtedly, have the targeting character. I will tell straight that in the light of data obtained by the modern sciences, the differentiation Cultura versus Natura, that used to be clear (in the time of Kant and Herder), has lost this characteristic. However, another evidence and another differentiation have occurred: the mechanism of creating values as such in its actual opposition to the natural goods of life has been uncovered. It has been uncovered in the character of the modern excessive consumption society and, in its utmost variant, in the way attractive images of Evil are produced. If Aristotle was "naively" thinking that "the thing being

3 In this work Heidegger shows that the essence of the Truth is the freedom that is being understood as openness to the Being. 
appraised and valued" shall remain to be the Good in some sense (Plotinus is indicative in this respect: "The Good is the Good not because it is being desired, but, on the contrary, it is being desired and looked for, because it is the Good" [4 (The Enneads. VI.7.24)]), then a modern consumer does not cherish any illusions concerning this, clearly understanding that the things that he/she values represent the pure Evil (in simple terms - "harms his/her life").

It is needed to add to the above-stated the following: the opinion that - ancient Greek and Middle Age thinkers did not see common aspects in ethical, esthetical, economical (and political) Values and because of this had not created a common Theory of Values - is basically mistaken. If the position of such "a fundamental systematist" as Aristotle is taken as the basis, then it will be difficult to find another study on the Good that would be more systematic and expanded within the entire history of philosophy, having in mind that reflection on the Good penetrates almost all his works ${ }^{4}$. But this is upon the condition that we will equate the Good and the Value. If these categories are distinguished, then it is needed to note, that Aristotle directly argues against an opportunity for existence of one science about the Common Good that has been obtained by means of induction [5 (Great Ethics, 1182b and further)]. And this simple inductive operation is the activity that the universal axiologist is trying to conduct. And Aristotle does not see an opportunity to bring all types of Goods to a common denominator, to combine those ethical, aesthetical, economical, political, and other Values which the universal axiology is based on. "Therefore, Stagirite says, it is easy to see that there is no single science or skill that would examine all Goods together" [Great Ethics, 1183a5]. Aristotle unambiguously named his position as dialectical, and within its frameworks, he always realized the difference between a formal combination of notions and their dialectical synthesis. In this case it was clear to him that if the Value in the form of the Evaluation ( $\dot{\alpha} \xi$ ló $\omega$ ) and the Value in the form of the Good (A $\gamma \alpha \dot{\alpha} \theta \omega v)$ are combined in one rubric, then both things will lose their meaning.

Plato, as Aristotle and Thomas Aquinas, clearly understood that there is the Good (or the Goods) and there is a choice of Goods. The Good as things is existence (these are the things that give life to everything, including such natural Goods as air, sun, and water) and the process of evaluation and choice of Goods have different nature. Any attempt to neutralize the opposite statuses of the Good as things in existence and the process of choosing the Goods will lead to a complete invalidity of the Value Theory. On the contrary, the rescue of the Theory consists in understanding the Values within the frameworks of the immanent procedure of making a choice figuratively speaking of "Goods" - because not all Values, and the more we go, the less Values conform to real Goods and, as such, require gratitude. Evaluation (as acknowledging the thing to be the Value) and gratitude are the subject's

4 Entire - "The Nicomachean Ethics" and "Great Ethics", "Politics", partially in "The Art of Rhetoric". opposite intentions and concealment of this difference represents one of "the fascinating" results of the work of the universal axiology.

Aristotle has not passed the question on emergence of the Value and noted an almost obvious thing: striving for this or that Good is a needed activity and a product of the targeting process. "The Goal always represents the Good of some sort" [5 (Great Ethics,1182a30)]. But in what sense? - he asks. In the sense that like the Goals, like the Values. An ability for setting Goals (from Aristotle to Kant) has always been thought of as an essential trait of a mind. For Kant it was enough to point at "the supreme goals of the mind" in order not to allocate Values into a special "axiological sphere". Some of his followers (Neo-Kantians) thought it was possible to extend his idea here.

Here it becomes important to summarize the common position of ancient Greek and Middle Age thinkers on the correlation between the Pure Good and the Values. They clearly understood the difference between the things thanks to which all things exist, including a human life and that's because of this it requires gratitude and the situation "there is choice and its declination, when it is up to us to choose between action and inaction" [5 (The Nicomachean Ethics, 1197a)]. The Good is the Pure Good when it is vital and the Good is the Value when it is chosen among many other goods. (At that, it becomes possible that the Pretend Good is chosen). We cannot choose: to breathe with air or not, to drink or not, to have parents or not. Because of this impossibility to choose, the category of the Goods was being filled with skills, talents, and virtues that are given to a person inherently. The Good determines the goals of a sensible being, that a person is. An absolutely different situation emerges when it is possible to choose the Goal. Only an object of a formally free choice may become and becomes the Value ${ }^{5}$. Therefore, it turns out that Goals determine Values. Under this approach, there is no need to create a separate "Theory of Values", because anything that can be said about Values is already contained in the choice of Goals.

\subsection{The World of Values: How a Consumer of Goods Sees It Today}

The differentiation of the Good and the Value, that was so clear for consciousness (of course, educated one) in the times of Ancient Greece and Middle Ages, not only cannot be comprehended by a collective consciousness of the modern epoch - its bearer actively resists the situation when the thing that he/she considers to be the Value could be something different from the Good. Using my own communication experience, I can state that: a modern individual, as a rule, sees the world in such a way that to value and love, to express gratitude and to evaluate the gifts, to choose between economical, ethical, and aesthetical Values means the same

\footnotetext{
5 The choice is formally free in accordance with general differentiation of "freedom for" and "freedom from". The freedom of consumption refers to the second type, i.e. as freedom from force.
} 
thing on a psychological level. Any attempts to impute such differentiation are perceived by an individual as assaults on his/her sacred right to choose the Goods freely. Of course, some historical conquest is seen in this. In this context a battle for "the Supreme Values" is being developed. Here the same differentiation, that was implied by ancient Greek and Middle Age thinkers, is being stated, only it is being done not on the level of ontology, but upon the conditions of normative conventionality. The thing, that in former times would be simply named as the Good, now is established normatively as the Common Value (that is obligatory for following), as the right for life (the Value of life), education, work, and etc.

The world of Values has a clear economical background, that universal axiology is denying any connection with. Axiologists have put a lot of efforts to tear the notion of Values away from the price and the estimates. And this is done when the estimates act as an empirical subject of the research of the Values (in all inquirers designed for this purpose), i.e. when a respondent is estimating the value of the thing, event, or his/her own state. But as soon as we ask what these aesthetical, ethical, religious, political, and economical Values have in common, then, because of a logical (here - inductive) necessity, we force ourselves to put the simplest denominator out of this entire variety (that is placed in a numerator). The Value that is determined economically becomes this denominator. As a matter of fact, the entire axiological rationality is built within the frameworks of the utilitarian logic of economic rationality, and, if to put it in extremely prosaic way, then market behaviour of a consumer represents model axiological behaviour. At the market a customer always evaluates the Good being purchased with regard to the correlation of its subjective value and expenses ${ }^{6}$. This logic is projected to spiritual Values as well.

The entire axiology is nothing else than concealed examination of the world of culture from the position of its "artificial" origin, i.e. from the point of it being produced, exchanged, and consumed. In this very dimension, the works of art become aesthetical Values (they are offered for sale and measured by price), religious principles become "traditional Values", moral obligations are perceived within the categories of utilitarian usefulness and exchange.

The most remarkable thing here is how a mass consumer starts to perceive the works of art. He/she thinks that these things emerge in the same way as mass production items and, therefore, their price determines their quality (bestseller). Consumer consciousness knows little about an actual process that in reality "produces" artistic creations and about the position of a real artist who in the last turn consideres himself as the author of this work. Heidegger in his fascinating work "The Origin of the Work of Art" determines the essence of the art as "considering the truth in the creation". A good

6 The marginal approach, that predominates in the economical science, is exactly about this. The marginal utility principle, that is being declared here, precisely characterizes the essence of axiological rationality. creator only incidentally produces some Values - in reality and originally - he is realizing his creative skill [13], that he uses to enrich his birth culture. Contents of any birth culture in no case can be presented as a combination of artificially created Values - originally it is the Collection of gifts of its great creators that determine the sense-bearing contents of this culture. And only then in the consciousness of a common citizen, who does not have any valuable artistic experience and who has received an opportunity to choose from this Collection of gifts, the works of art are put in this or that hierarchical order of artistic Values.

For everyday consciousness, culture is represented not with its originative (creative) processes and regulatory principles, but with its materialized results - exactly as a set of artificially created Values. This position has its truth. Culture, in its result, really is a set of created and exhibited at choice Values. But only, as Hegel always used to state: "the result, that has left the process behind, is dead". Demonstrativeness of opposition of all artificial things to essential ones closes relations and processes, that originate culture, to such consciousness. Communication (language) acts as the first and the main process out of all these processes. Language is "the spirit of the nation" (W. Humboldt) and the very essence of culture, its constitutative principle - and it is extremely far away from any artificial origination. Putting a human language into an opposition to nature (including human nature) has no special sense, because only it allows to understand how a person gets to know nature and can produce technical devices.

Universal axiology (the position that puts Values into the foundation of the cultural theory) is nothing more than an ideology of a consumer society, if this, within the positive frameworks, implies the sacred right of a consumer to choose the Goods. Axiology establishes the right of the subject to estimate the Goods and create (form) Values that, in a strict sense, do not represent Goods any more.

But this theory may have another status. If it announces itself to be a philosophical theory, then it must take a critical position and become critique of axiological rationality. It is possible to save axiology from ideological bias, but the only way for doing this is to take the process of origination of Values as its main subject.

Under this approach the problematics of the Theory of Values will be focused around the question: what transformation senses of human existence and the Goods of Life undergo when they are included into the context of economically determined existence. At that, it becomes clear that so called aesthetical, religious, and moral Values represent economically transformed forms of special senses of human existence-in-the-world, the thing that is commonly referred to as "simulacrum" in the modern discourse. It is needed to state here that testing for simulacrum has always been, and today, more than ever, becomes a mission of the critical reason of philosophy. 


\section{The Attitude to Values in Modern Philosophy}

The attitude to Values in the modern philosophy, basically, has little or no difference from the times of ancient Greece or Middle Ages. The essential commonness of the philosophical thinking of these two, though very different, epochs lies in the fact that the first one does not exist within the subjectobject paradigm, and the second one moves beyond it, asking who comes after the subject? [14]. Meanwhile, Values represent manifestations of human subjectivity (this is declared by axiology itself) and borders of the value-based attitude to the world go right along its "remains". The thing that can be named as "the modern philosophy" (meaning "the epoch embraced in the notion") has evolved from inavailability to continue thinking of a human language and technology (two poles that constitute culture) as a "mixture" of subjective and objective things. "A question about the technology", as it is set by modern thinkers ${ }^{7}$, and "a linguistic turn" determine the main circle of interests and the trend of the modern philosophical thought. All significant theories think that Values have been derived from something else, and it means that they are inexplicable out of themselves. Followers of Marks deduce them from the class position of the subject; psychoanalysis looks at them in a symptomatic manner as manifestation of unconscious attitudes and/or symbolist order; hermeneutics and analytical philosophy think of them as the things derived from the usage of the language; classical phenomenology finds a special place for them in the structure of consciousness; fundamental ontology looks at them through the phenomenon of throwness; postmodernism sees in them, mainly, simulacra. It is not surprising that the modern philosophy has formed a rather critical attitude and unusual professional consensus concerning the place that is taken by Values in the life of a person, culture, and society. For more details, please, see [15]. This topic can be broadened, but it is thought that within this context it is sufficient to point at the state of facts, namely to indicate that the modern philosophy does not consider Values to be the fundamental foundation of the Being of a person and culture.

It is useful to pay special attention to the reputable position of representatives of the communitarian project of the modern society (A. MacIntyre, C. Taylor, A. Etzioni), as thinkers, who aim bringing a classical idea of the Good in its opposition to the idea of the Value back into the philosophical discourse ${ }^{8}$. They sharply raise the question that has become practically the most crucial one for the modern humankind: what are the conditions for the possibility that people and cultures following different Values can come to an

7 The question about the technology, that has been raised in the philosophy since the beginning of the $\mathrm{XX}$ century, has become especially sharp in relation to penetration of the technologies into the depth of the very "Nature". Options of genetic transformations and experiments on live organisms do not allow to unquestionably oppose artificial and natural things.

8 O.B. Davydov has drawn my attention to the position of the communitarists in this matter. agreement on norms of collective co-existence? Can the normative order of co-existence be reduced to the valuebased one? These questions are being asked whereas it is obvious that it is impossible to reach any consensus and form a stable community within the frameworks of the logic of formation of Values (even if we are talking about "the supreme ones").

In relation to the questions that have been posed, $\mathrm{C}$. Taylor (in his work "Sources of the Self") develops a major study on how modernistic axiologic narrative is appearing and functioning and how it opposes itself to the classical philosophy of the Good. The author shows that it only seems that Values are universal, in reality, substantive understanding of the Good lies in the foundation of the collective being of people. "We feel in the very experience of existing that we are moved by some supreme Good, that we are touched by it, but not that it is valuable because of our reaction" [16]. Recognizing that individual and social identities are formed not with the Values, but with the Good, though its sense is being interpreted differently - this acts as a condition for existence of the society itself and peaceful dialog among various cultures. Axiological discourse by itself unites with one and disconnects with the other, and, as such, in fact, it does not contribute to mutual understanding. Therefore, as Taylor says, refusing the ideology of the Values is vitally important for the modern humankind. The author understands that different groups, countries, religious communities, and civilizations may have irreconcilable ideas concerning the human nature, the place of the person in the world and his/her relations with the God, but he admits that "real, free consent" may be reached if participants of the dialog agree on norms, but disagree on their explanations. Participants of the dialogs will keep to this consensus "without thinking about differences of Fundamental Values".

Another representative of the communitarian project - A. Etzioni - is developing a concept of "Good Society" based on the principle that people have a conscious consent to live together [17]. This consent cannot be ensured within the frameworks of the dispute on Values. Etzioni notes that experts (and it is needed to add here - the people in power, their ideologists and propagandists) usually act as translators of the value-based discourse, whereas the existence of "Good Society" needs all citizens to take part in the dialog on the Good. The reason for holding this dialog implies not an abstract set of Values, but variative beliefs about good living, that are relevant to the idea of the Common Good.

The same problem, only in a peculiar ethical way, is being developed by A. MacIntyre. He sets the priority of classical virtue ethics on the ethics of axiological discourse [11]. In complete compliance with ancient Greek and Middle Age philosophy of the Goods, the author thinks that aiming for the Good is immanent to the human nature. Meanwhile, from the position of the axiology - Values are transcendent to the human nature. Therefore it turns out that the idea of the Value cannot serve as a final explanation of human morality.

But, of course, the universal Theory of Values (this is the theory that considers Values to be the foundation of culture) 
has rational sense, and the only thing that it can be reproached of is its hypertrophy of the reasons. Here it is needed to clarify the border that axiology crosses in its attempt to universalize the world of Values.

There is one quite obvious circumstance that is accepted by all researches of culture: a person acts, perceives and thinks in accordance with some exact cultural samples (types, schemes, models, patterns, and etc.) that he/she uses to compare the reality with and, in compliance with which, he/she is aiming to transform this reality.

With regards to the ontological status, these samples have ideal (meaning non-material) character. Why can't this cultural conditioning of the human existence be interpreted in an axiological way, and then can't we, with charming simplicity, state that the Value is "an ideal model of some phenomenon" [18]? The position of I.I. Dokuchaev is indicative in terms of "universalist pretentions" of axiology. As all similar pretentions, this one is based, in some way, on an aim to objectify Values and present them as the human (subjective) way of reflection of the Being. Here the main peculiarity of an axiological reason is emerging: an aim to press the great idea of the Good under the Values by simply ignoring their different ontological status. The Values really could not exist if the Being was not the Good, but the Good is not responsible for the willfulness of the human Values (Christian thinkers had to underline this). Attempting to "fit" anything that refers to the idea of the Good into the concept of the Value leads to ambiguity and evasiveness of further statements. Among which there are the following: excluding the Truth from the Values [18], attempting to fence Values off Disvalues and Countervalues [18]. This also implies, on one hand, an optional expansion of the amount of the notion "Value", and, on the other hand, reduction of the range of those phenomena that are supposed to be included there.

The main aporia of the universal axiology lies in the fact that it cannot be universally applied to researches of real human communities. Each time we will encounter fundamental differences between "value-based matrixes" and "ideal models" of castes, classes, social categories, and stratified social groups - it is possible to talk about the common culture of them, but only if basing on neutral valuebased symbolic systems (a language, kinship systems, rituals, and etc.) and communicative mechanisms in accordance with which they are transmitted from generation to generation.

Defining Values as "ideal models" seems to be vulnerable from two sides.

Firstly, this definition significantly expands the notion, it urges to include into the range of Values the things that, by axiologists' own admission, do not belong there. If this definition is taken literally, then the notion of the Value shall cover all idealized models, including theoretical ones (the ones that claim to be True). But in accordance with the axiology (and the author is consistent here): "The Truth is in no way the Value" [18]. However, if, on the contrary, a capability of a human mind to imagine idealized models is being looked at genus, that really constitutes culture, and axiological models - as species and special "surface" modus of culture, then we will come back to a classical philosophical position that did not consider it was needed (and not because of some thoughtlessness) to create a special Theory of Values. This is the reason why Kant and Hegel did not think it was needed to create a special Theory of Values, because, in their opinion, the ability of the mind was enough for them to correlate the object with its notion (the idea, the universal). In this context, Hegel defines the Truth as a measure in accordance with which the object corresponds to its notion. He says: "This deeper sense of the Truth is being talked about, when speaking about the True State or the True work of art. These objects are true, when they represent the essence that they should be, i.e. when their reality corresponds to their notion" [19]. In the spirit of classical philosophy, an ideal state, person, work of art, and etc. are being thought of within the paradigm of the Pure Good, i.e. the things that "give good to the others", which correlates to its reason for existence or its ideal intent. Though, there is a reason to think that the classics had been pressing the Values under ratio for too much, but they, nevertheless, left some space for them. On the contrary, reducing the culture to the Values has less ground for doing this. The state, family, art have their own intents, and, in this sense, they act as the Unconditional Good for the human existence. And the question asking to what extent these Goods are considered to be "valued and appraised" in this culture or epoch is not irrational. But to derive an essential characteristic of a culture out of this information is, at least, naïve. The question about the meaning of attributes of human existence cannot be packed into the narrow channel of axiology. The first thing that will not fit there is the conceptual core of the culture - its language. This is the reason why field researchers of culture do not take Values, that are followed by some cultural community, as their subject, instead they take its symbolic structures that transfer meanings from generation to generation. Axiological measurements of cultures represents "foam on the surface of deep-water currents" for anthropologists of the caliber of B. Malinowski, C. LeviStrauss, C. Geertz, L. White, G. Murdock, and etc.

It is certain that in majority of cases an individual attributes some value to the model, but, taking into account the fact, that different individuals, understanding what is implied, nevertheless, attribute different degree of value to it - indicates that Value is secondary to the sense. Consider a case of "an ideal model of a family", for example. Before giving any value to the concept of a family, it is needed to have an idea (to understand the sense) of what it is. And this is true in all cases: before a value-based model originates, there shall be a sense-bearing (representative) model: what a family is, what the state is, what poetry is, and etc. Only after this, the model can obtain this or that value.

Generally speaking, substituting the Truth with the Evaluation is characteristic for axiological rationality. Where classical philosophy talks about the Truth and the Knowledge, an expert thinking axiologically will make evaluations. Where classics used to tell about the mind in its ability to gain the Truth, an expert starts passing judgments 
on its efficiency.

On the other hand, and, secondly, this definition of Values equally improperly reduces the range of the phenomena that we have become accustomed to consider to be Values of the culture. The culture of a real community of people represents (among other things) a quite concrete collection of creative gifts of the geniuses of the group. Their works have exemplary or even - model - character for this culture, but in the opposition "ideal - real" these works take the position of the real culture, i.e. it is difficult to define them as "ideal models".

Consider, for example, Pushkin's creation that represents the Pure Good for Russian culture and its greatest "Value". The question on identifying the meaning of Pushkin's creation for formation of Russian culture is, first of all, not the question of Evaluation and Value, but it is the question on determining the real state of facts: who and what his creation "has given life to" in this culture. And an absolutely special question (that cannot be ignored) - to what extent and how this or that generation values Pushkin. To put it shortly, researching the Goods of the culture and researching the Values of the culture represent two different research programs.

The Russian cultural studies have place for another concept of culture that is more fundamental with regards to the amount of the covered material, it is based not on the idea of the Value, but on the idea of the Sense. A.A. Pelipenko [20] follows a sense-bearing approach to culture, for him (as well as for the author of these words) original value-based neutrality of the Sense and conceptualization represent a principle position. It may be also said that the Values only "represent movement of senses that set the basic vector for existence of a person in a culture" [21]. An alternative model of culture puts an emphasis not on the Values, but, as it is, on the way they are being transferred from one subject to another or from one generation to another. This transfer ensures continuity of not only and not so much Values, but stored knowledge and skills. T. Parsons chooses a good name for this social transfer, he calls it "a storage of a cultural type?" [22]. This approach states that the Value can save itself in the history upon the condition that its sense will be clear for an addressee. This is why culture, firstly, is the medium of the sense, it is a historical process for storing cultural patterns - and, only secondly (and even thirdly), it is the matrix of these or those Values. When researching the Values, we have to ask not only what they are, but also how they preserve themselves in the history, and what mechanism helps to transfer them. Focusing on such dynamics of culture is much more important from the theoretical and methodological points of view, rather than describing the Values that exist in the culture.

\section{The Mythology of Values}

Some well-known topics can be used to criticize axiological rationality. The first of them is "Critique of modern mythology": its initiator has been R. Barthes [23].
The author's achievement here is that he has explained a semiologic mechanism of formation of mythic structures of consciousness as displacement and substitution of primary meanings to secondary and tertiary ones. Understanding this mechanism allows to notice that Values are being formed at the level of secondary meanings, and, therefore, it always involves formation of simulacra. Political ideology and commercial advertising function within the frameworks of this logic of the myth. Barthes has shown that production of myths (ideologemes) has become one of the basic mechanisms for legitimatization of social order in the modern society. At that, it turns out that people take different positions in the system of modern mythology. Some of them produce myths, some - consume them, and others can take a critical look at them. This distribution has been developed in a well-known work of P. Sloterdijk "Critique on cynical reason" [24]. The cynical reason is the one that understands how the modern mythology works and resigns to its inevitability. Within the frameworks of the set topic of "cynical reason", I would like to add that "cynicism" characterizes only small part of a society - those who take part in production of political, market, and cultural myths, and a large proportion of those who criticize this process. Consumers of the modern mythology can be hardly ranked as cynics. A myth is a structure of trust that is being developed in communicative space [25]. The person who trusts is not cynical; he/she is naïve and this is not his/her moral flaw. This is why his/her consciousness is being applied with positive critique of naïve ("natural") consciousness that constitutes particular pathos of the modern phenomenology. The critique shall be positive in the sense that is can warn "a naïve person" about "cynics" attempting to fool him/her. So, it turns out, that social consciousness folds out to two poles that are here determined as "cynical" reason and "axiological" reason.

The formula of cynical reason, that is suggested by Sloterdijk, is the following: "They perfectly realize what they are doing, but, nevertheless, they continue doing this". Then axiological reason represents a reverse side of cynical reason. An intention to give a private interest to a common one (this, as Marks says, is the core of an ideology) can be brought into existence only upon the condition that there are "naïve people" who take someone else's and private interest as the common and personal Value. Transformation of political and economic interest in the Value of mass consciousness is the thing that is suggested to be seen by the critique of modern ideology. S. Zizek (referring to Sloterdijk) is summing up.

"The very essence of the ideology implies some initial, determinative naïveté: false understanding of one's own presuppositions, one's own actual conditions $<\ldots>$. The cynical reason is not naïve any more, it paradoxically turns out to be enlightened with false consciousness: it understands perfectly well the falsity, fully realizes that private interests stand behind ideological universals, and it has no intention of giving these universals up [26] <... . Cynicism is the response of the ruling culture to such cynic downfall: it recognizes, takes into account the private interest standing 
behind ideological universals, the distance that divides the ideological mask and reality, however it has its reasons not to give this mask up. This cynicism does not frankly represent an amoral position, it is rather that the very moral here is at the service of amoralism" [26].

A universal axiologist, whether wishing or not, becomes an ideologist of mass consciousness that organically is not capable of recognizing actual state of things behind the Values that are being inflicted to him/her. Besides this, behind the Value there always stands a person who is claiming it. This is exactly why the classical Marxist critique of ideology can be expanded to the entire axiology. An ideologist is always an axiologist in practice, whose aim is to establish certain Values (patriotism, spirituality, family values, and etc.) in a society. The thing is not that patriotism, family, or spirituality cannot act as Values (Goods) for a human community, but in the way they are being established. They are being established within the modality "you must", but not "you can". "You must" excludes the question "why". (Compare: Kant: "you must, because you can". You can, because this complies with the internal necessity of your nature (as Spinoza also states), and therefore you - must).

Marxists own an important idea that is somehow lost in the modern cultural researches. This idea is about two cultures: culture of the ruling class and culture of the suppress class. With all the changes of the class approach (that has not at all outlived its usefulness [27]), it remains unaltered that speaking about the culture in a theoretical way as about the system of some definite Values is impossible. It can be presented as accumulated wealth of artefacts, i.e. in a strictly empirical way, but to substantiate a theoretic and system base in the form of axiology and do this methodically accurate means to show ideological naivety. This is exactly from an axiological point of view, that national culture (that is really clamped with common ideas that are being carried by the national language, "the spirit of the nation", as Humboldt says) looks like the Kunstkammer where all people are looking at what is interesting for them. How can the God be the Supreme Value for an atheistic part of the society? Shall patriotism be the Supreme Value of a citizen? What is more important for you when you are making a value-based choice: equality or freedom? Every time when we establish something as a Value, we immediately find (and this is within this one cultural community) unsurpassable disagreement among its members. And this very disagreement is possible only because these people belong (strangely enough) to one culture, because they speak the same language (in a syntactical grasp of the language - as it is stated by the modern linguistics). As a result, it becomes impossible to bring this culture to a common axiological denominator and regulate its components upon such terms. Culture has no axiological order in a stratified ("class") sense, but it has no such order in a historical perspective as well. What basic Common Values can we identify in this definitive historic community that is being named Russian (Chinese, French, and etc.) culture? "Monarchy, Orthodox Christianity, National Spirit" represent mythologemes of the Russian
Empire, which value-based structure differs radically from the Values of proletarian internationalism, atheism, and popular representation of the Soviet times. A modern attempt to come back to an old mythologeme, to create the same value matrix as it was in the Russian Empire is doomed to failure in advance, because the historic logic of culture is determined not with the set of Values, but with the transfer of the Sense from generation to generation. The logic of a sense-bearing transfer, that ensures unity of the native culture, cannot be grasped by axiology, but it becomes clear only within the frameworks of the hermeneutics of culture. The ethical pathos of the hermeneutics lies in finding options to get over value-based beliefs of the participants of the dialog. Therefore, critique of axiological reason obtains a deep ethical meaning. Nothing can separate people in so sharp and hostile ways as the Values they follow.

\section{Conclusion}

Finally, the issue is about a necessity to conduct a differentiation: a differentiation between the things that we owe our human life to, the things without which it could not take place and the things that we can compare and choose by joining to them or taking them. This differentiation needs to be identified in some way. If the first category is identified as "the Goods", and the second as "the Values", then we will be able to see this differentiation close to the variant that was followed in the old days of ancient Greece and Middle Ages. But if we identify the first category as "Supreme or Absolute Values", and the second category simply as "Values" - then we will find ourselves in axiological aporia: it will be needed to explain the common things that form the world of Values in all their multiplicity (economic, aesthetical, political, and others). Axiological universalism denies itself when it is trying to find the unity of the Values in their own composition. As in a theoretical view, it is impossible to find a basis for the unity of the Values within these Values, so in a pragmatic view, it is impossible for people and cultures, that follow different systems of Values, to agree on anything within the logic of axiological rationality. The only real basis for unity of human communities can be represented with the Sense - the very form of presence of the unity in many instances. We can recognize the great idea of the Good in the image of the Sense of the Being of things in existence.

\section{Acknowledgements}

I would like to express gratitude to E. E. Drobysheva, the Doctor of Philosophic Sciences, and O. B. Davydov, the Candidate of Philosophic Sciences, for their remarks and corrections that have been included into the article.

\section{References}

[1] Kagan M. S. (1997) The philosophical theory of values, SaintPetersburg (in Russian). 
[2] Heidegger, Martin. (1993) Letter on Humanism, M. Heidegger, Time and Being, The Republic, Moscow. (Russian Translation).

[3] Fedchuk, Dmitrie A. (2016) The concept of value in axiology and scholastic notion of good, International Journal of Cultural Studies, Vol. 2, pp.52-61 (in Russian).

[4] Plotinus. (1995) Ennead, UTSIMM-Press, Kiev (Russian Translation).

[5] Aristotle. (1984) Works in 4 volumes. Vol.4. Moscow: Thought (in Russian).

[6] Nancy J. - L. (1994) Today, Ad marginem-93. pp. 148-164 (in Russian).

[7] Baudrillard, Jean (1990) La Transparence du Mal, Paris (in French. Russian Translation 2006).

[8] Bataille, Georges (1957) La Littérature et le Mal, Paris (in French. Russian Translation 1994).

[9] Badiou, Alien. (1993) L'Éthique. Essai sur la conscience du mal, Hatier, Paris (in French. Russian Translation 2006).

[10] Joas H. (1999) Die Entstehung der Werte, Suhrkamp, Franfurt am Main (in German) Russian Translation: Joas H. The appearance of values. Saint-Petersburg: Aleteya 2013.

[11] Macintyre A. (1981) After virtue. A study of moral theory, Norte Dame University Press, Indiana.

[12] Heidegger, Martin (1991) The Essence of Truth, Heidegger M. Conversation on a country road. Higher School, Moscow, pp.8-27 (Russian Translation).

[13] Hyde, Luis. (1983) The Gift. Creativity and the Artist in the Modern World, Canongate, Edinburg, New York, Melbourne.

[14] Who comes after the Subject? (1991) Ed. By E.Cadava, P. Connor, J. - L. Nancy. N. - Y.

[15] Yachin, Sergey E. (2016) Meaning and values. Critique of the theory of value in modern philosophy, International Journal of Cultural Studies, Vol.2 (2016), pp.27-39 (in Russian).

[16] Taylor, Charles (1989) Sources of the Self: The Making of the Modern Identity. Harvard University Press.

[17] Etzioni, Amitai (2000) The Third Way to a Good Society/ Demos.

[18] Dokuchaev, Ilya I. (2009) Value and existential. Basic principle of historical axiology of culture, Science, SaintPetersburg (in Russian).

[19] Hegel, Georg. (1975) The Encyclopedia of the Philosophical Sciences. Vol. 1. Moscow: Thought.

[20] Pelipenko A. A. (2012) Comprehension of culture. At 2 part. Part I. Culture and meaning. Russian Political Encyclopedia, Moscow (in Russian).

[21] Drobysheva, Elena E. (2010) Architectonics of culture: experience of philosophical reflection of culture. SaintPetersburg: Publishing house SPbSUSE, 2010 (in Russian).

[22] Parsons Talcott. (1937)The Structure of Social Action. McGraw Hill Book Company, Inc. (Russian Translation 2000).

[23] Barthes, Roland (1957) Mythologies, Seuil, Paris (in French. Russian Translation 1989).

[24] Sloterdijk, Piter. (1983) Kritik der zynischen Vernunft. 2 Bände. Suhrkamp, Frankfurt am Main (in German. Russian Translation 2001).

[25] Yachin, Sergey E. (2002) The human in the sequence of events of sacrifice, gift and exchange. Dal'nauka, Vladivostok.

[26] Žižek, Slavoy (1989) The Sublime Object of Ideology, Verso, London.

[27] Jameson, Fredrik. (2007) Marxism \& Interpretation of culture. Armchair Scientist. Moscow. 